I. M. Stratton - C. A. Cull - A. I. Adler •

D. R. Matthews $\cdot$ H. A. W. Neil • R. R. Holman

\title{
Additive effects of glycaemia and blood pressure exposure on risk of complications in type 2 diabetes: a prospective observational study (UKPDS 75)
}

Received: 24 August 2005 / Accepted: 22 March 2006 / Published online: 31 May 2006

C) Springer-Verlag 2006

\begin{abstract}
Aims/hypothesis: The relative importance of glucose and blood pressure control in type 2 diabetes remains uncertain. We assessed interactive effects of glycaemia and systolic blood pressure (SBP) exposure on the risk of diabetic complications over time. Subjects, materials and methods: $\mathrm{HbA}_{1 \mathrm{c}}$ and SBP, measured annually for a median of 10.4 years in 4,320 newly diagnosed type 2 diabetic patients from the UK Prospective Diabetes Study (UKPDS), were categorised as updated mean values $<6.0,6.0-6.9,7.0-7.9$ or $\geq 8.0 \%$, and $<130,130-139,140-149$ or $\geq 150 \mathrm{mmHg}$, respectively. Clinical outcomes were UKPDS predefined composite endpoints. Results: The incidence of the 'any diabetes-related endpoint' in the lowest $\left(\mathrm{HbA}_{1 \mathrm{c}}<6.0 \%\right.$, SBP $<130 \mathrm{mmHg})$ and highest $\left(\mathrm{HbA}_{1 \mathrm{c}} \geq 8 \%\right.$, SBP $\geq 150 \mathrm{mmHg}$ ) category combinations was 15 and 82 per 1,000 person-years, respectively, and 24 and 120 per 1,000 person-years in a Poisson model adjusted to white Caucasian male sex, age 50 to 54 years and diabetes duration of 7.5 to 12.5 years. Updated mean $\mathrm{HbA}_{1 \mathrm{c}}$ and SBP effects were additive in an adjusted proportional hazards model with risk reductions of $21 \%$ per $1 \% \mathrm{HbA}_{1 \mathrm{c}}$ decrement and $11 \%$ per $10 \mathrm{mmHg}$ SBP decrement. Endpoint rates obtained in the 887 patients randomised
\end{abstract}

I. M. Stratton · C. A. Cull · A. I. Adler · R. R. Holman ( $₫)$ Diabetes Trial Unit,

Oxford Centre for Diabetes, Endocrinology and Metabolism,

Churchill Hospital,

Oxford, OX3 7LJ, UK

e-mail: rury.holman@dtu.ox.ac.uk

Tel.: +44-1865-857240

Fax: $+44-1865-857241$

D. R. Matthews · H. A. W. Neil

Oxford Centre for Diabetes, Endocrinology and Metabolism,

Churchill Hospital,

Oxford, UK

\section{H. A. W. Neil}

Division of Public Health and Primary Care, Institute of Health Sciences, University of Oxford,

Oxford, UK in both the glycaemia and hypertension intervention trial arms were consistent with the observational data. Those allocated to both intensive glucose and tight blood pressure control policies had fewer events than those allocated to either policy alone or to neither ( $p$ for trend 0.024). Conclusions/interpretation: Risk of complications in type 2 diabetes is associated independently and additively with hyperglycaemia and hypertension. Intensive treatment of both these risk factors is required to minimise the incidence of complications.

Keywords Blood pressure - Complications · Glycaemia · Risk - Type 2 diabetes · UKPDS

Abbreviations BP: blood pressure - SBP: systolic blood pressure - UKPDS: UK Prospective Diabetes Study

\section{Introduction}

In patients with newly diagnosed type 2 diabetes, the UK Prospective Diabetes Study (UKPDS) showed that an intensive compared with a conventional blood glucose control policy reduced the risk of developing any diabetic complications [1]. Microvascular complications were reduced significantly with a borderline significantly reduced risk of myocardial infarction $(p=0.052)$. In a subset of UKPDS patients who also were hypertensive, tight compared with less tight blood pressure (BP) control reduced the risk of developing macrovascular and microvascular complications of diabetes [2]. Observational analyses of UKPDS data have confirmed independent associations of $\mathrm{HbA}_{1 \mathrm{c}}$ and systolic BP (SBP) levels over time with diabetic complications $[3,4]$ with no evidence of any apparent threshold of risk across the range of $\mathrm{HbA}_{1 \mathrm{c}}$ and SBP values studied. Although it is now known that therapies to lower $\mathrm{HbA}_{1 \mathrm{c}}$ and SBP can reduce the risk of diabetic complications $[1,5,6]$, it remains uncertain whether treatment of either alone is sufficient, or whether, to obtain maximum benefit, both of these risk factors need to be treated simultaneously [7]. A multiple risk factor 
intervention trial in type 2 diabetes has shown that increased benefit can be obtained by targeting several risk factors simultaneously [8].

To determine whether the associations observed between the risk of developing diabetes-related complications and different combinations of $\mathrm{HbA}_{1 \mathrm{c}}$ and SBP levels over time are additive, we undertook further observational analyses in 4,320 UKPDS patients with the requisite data available. To investigate the extent to which a combined therapeutic approach of simultaneously improving both blood glucose and BP might confer greater benefit than by treating either alone, we examined the clinical outcomes that occurred in the 887 hypertensive UKPDS patients who were randomised in both the glycaemia and hypertension intervention arms of the study.

\section{Subjects, materials and methods}

\section{Patients}

The UKPDS recruitment and selection process has been reported previously [9]. The study received ethical committee approval in each of the 23 clinical centres and conformed to the guidelines of the Declarations of Helsinki (1975 and 1983). Briefly, 5,102 of the 7,616 patients referred were recruited. The patients, all of whom gave informed consent, were aged 25 to 65 years with newly diagnosed type 2 diabetes and fasting plasma glucose levels $>6.0 \mathrm{mmol} / \mathrm{l}$ on two mornings after referral. Of the 5,102, 81\% were white Caucasian, 10\% Asian-Indian and 9\% Afro-Caribbean. Exclusion criteria included severe vascular disease, a myocardial infarction or stroke within the previous year or a major systemic illness.

The 3,867 of the 5,102 patients who continued to have fasting plasma glucose levels in the range 6.0 to $15.0 \mathrm{mmol} / \mathrm{l}$ after a dietary run-in period were allocated randomly either to a conventional glucose control policy treated primarily with diet alone or to an intensive glucose control policy treated primarily with sulphonylurea or insulin [1]. In a factorial manner, 1,148 of the 5,102 patients, who also were hypertensive, were randomised in addition either to a tight or to a less tight BP control policy. Of these 1,148 patients, 758 were randomised to a tight BP control arm and allocated to therapy primarily with an ACE-inhibitor (captopril) or a beta-blocker (atenolol), whereas these therapies were avoided in the remaining 390 patients allocated to a less tight BP control arm [9-11].

\section{Glycaemic and BP exposure}

Of the 5,102 patients recruited into the UKPDS, 4,320 had $\mathrm{HbA}_{1 \mathrm{c}}$ and SBP measurements available at baseline, following the dietary run-in period, and annually thereafter. $\mathrm{HbA}_{1 \mathrm{c}}$ was measured by HPLC using an automated glycosylated haemoglobin analyser (Diamat; Bio-Rad Laboratories, Hemel Hempstead, UK), (non-diabetic range $4.5-6.2 \%)[12,13] . \mathrm{HbA}_{1 \mathrm{c}}$ measurements were certified comparable with those of the DCCT by the US National Glycohemoglobin Standardization Program. Glycaemic exposure over time was assessed as the updated mean of the annual $\mathrm{HbA}_{1 \mathrm{c}}$ measurements, calculated for each individual from baseline to the last year of follow-up or to the last value before the occurrence of a predefined UKPDS endpoint. BP was measured by a trained nurse using an electronic sphygmomanometer (Copal UA-251 or Takeda UA-751; Andrew Stephens Co., Brighouse, West Yorkshire, UK) or a random zero sphygmomanometer (Hawksley \& Sons, Lancing, Sussex, UK) [11]. The first reading was discarded and the mean of the next three readings with a $\mathrm{CV}<15 \%$ used. SBP exposure over time was calculated as for the updated mean $\mathrm{HbA}_{1 \mathrm{c}}$.

Only 887 UKPDS patients were randomised both to one of the two blood glucose control policies and also to one of the two BP control policies. Although this was done in a factorial manner, the randomisation ratios of $3: 7$ for conventional to intensive glucose control policies and 1:2 for less tight to tight BP control policies meant that unequal numbers of patients were allocated to the four possible randomisation combinations. Of the 887 patients, 87 were allocated to conventional glucose/less tight BP, 155 to conventional glucose/tight BP, 231 to intensive glucose/ less tight BP and 414 to intensive glucose/tight BP intervention policies.

\section{Clinical outcomes}

Patients were followed for a median of 10.4 years. UKPDS predefined endpoints were assessed independently by two clinicians who were masked to therapy allocations [9]. The three primary composite endpoints were: (1) any diabetesrelated endpoint (myocardial infarction, sudden death, angina, stroke, renal failure, lower extremity amputation or death from peripheral vascular disease, death from hyperglycaemia or hypoglycaemia, heart failure, vitreous haemorrhage, retinal photocoagulation and cataract extraction); (2) diabetes-related death (myocardial infarction, sudden death, stroke, peripheral vascular disease, renal disease, hyperglycaemia or hypoglycaemia); and (3) allcause mortality. The three secondary composite endpoints were: (1) myocardial infarction (fatal myocardial infarction, non-fatal myocardial infarction or sudden death); (2) stroke (fatal and non-fatal); or (3) microvascular disease (retinal photocoagulation, vitreous haemorrhage and fatal or non-fatal renal failure). The time to the first event within each composite was used for analyses.

Statistical analyses

\section{Overview}

Observational analyses were undertaken to determine the unadjusted and adjusted composite endpoint rates for different combinations of blood glucose and BP levels over time and to examine the degree to which these associations 
might be synergistic or antagonistic. In addition, we present the composite endpoint rates for the subset of patients who were randomised in both the blood glucose and BP control arms. All analyses were carried out using SAS v8.2 and 9.1.3 (SAS Institute, Cary, NC, USA). Data are presented as mean (SD), median (interquartile range) or geometric mean (1 SD interval), apart from incidence data, which are presented as mean $(95 \%$ CI). A $1 \%$ level of statistical significance was chosen to minimise potential Type 1 errors.

\section{Unadjusted incidence rates}

Updated mean $\mathrm{HbA}_{1 \mathrm{c}}$ and $\mathrm{SBP}$ values for each patient were categorised into four levels of glycaemia $(<6 \%, 6-6.9 \%$, $7.0-7.9 \%$ and $\geq 8 \%)$ and four levels of SBP $(<130,130$ $139,140-149$ and $\geq 150 \mathrm{mmHg}$ ). Composite endpoint crude incidence rates were calculated, as events per 1,000 person-years, for each of the 16 category combinations.

\section{Adjusted incidence rates}

Adjusted composite endpoint incidence rates for a normadjusted population were calculated for each of the 16 category combinations as events per 1,000 person-years using a Poisson regression model adjusted to white Caucasian male sex, age 50- to 54 years and diabetes duration of 7.5-12.5 years. The relative risk of the highest $\left(\mathrm{HbA}_{1 \mathrm{c}} \geq 8 \%\right.$, SBP $\left.\geq 150 \mathrm{mmHg}\right)$ to the lowest $\left(\mathrm{HbA}_{1 \mathrm{c}}<6.0 \%\right.$, SBP $\left.<130 \mathrm{mmHg}\right)$ category combination was determined.

\section{Potential additive effects of glycaemia and BP}

A proportional hazards regression model was used to determine the association between time to event, updated mean $\mathrm{HbA}_{1 \mathrm{c}}$ and updated mean SBP, and also to estimate separately the risk reductions for a $1 \%$ absolute decrement in updated mean $\mathrm{HbA}_{1 \mathrm{c}}$ and for a $10 \mathrm{mmHg}$ decrement in updated mean SBP. At each event time the updated mean $\mathrm{HbA}_{1 \mathrm{c}}$ and SBP values for individuals with an event were compared with the updated values for those who had not had an event by that time. Updated mean $\mathrm{HbA}_{1 \mathrm{c}}$ and SBP values were included as time-dependent covariates to evaluate glycaemic and BP exposure during follow-up. Risk decrease was defined as 1 minus the reciprocal of the hazard ratio. Potential confounding risk factors included in the models were: sex, age, ethnicity, smoking status (current/ever/never) at time of diagnosis of diabetes and HDL-cholesterol, LDL-cholesterol, triglycerides and albuminuria $(>50 \mathrm{mg} / \mathrm{l}$ measured in a single morning urine sample) immediately after the dietary run-in period. Patients were included irrespective of their randomisation to different blood glucose or BP control policies.

In addition to fitting $\mathrm{HbA}_{1 \mathrm{c}}$ and $\mathrm{SBP}$ as continuous variables for each of the composite endpoints under consideration in the proportional hazard model, a product term for these two factors was also included to test for possible interactions.

\section{Randomised glycaemia and BP intervention trial}

The small number of patients randomised into both the glycaemia and BP intervention arms of the UKPDS meant that there was insufficient statistical power to undertake specific analyses of the composite endpoints obtained in the four combinations of allocated glucose and BP control policies. To estimate the extent to which the factorial intervention trial might be in accord with the observational analyses presented here, we have examined, on an intention-to-treat basis, the composite endpoint incidence

Table 1 Clinical characteristics of the UKPDS patients included in the observational analyses and of the subset who were randomised in both the glycaemia and hypertension intervention arms of the trial

\begin{tabular}{|c|c|c|}
\hline & $\begin{array}{l}\text { Observational } \\
\text { study }\end{array}$ & $\begin{array}{l}\text { Randomised intervention trial } \\
\text { of blood glucose and BP }\end{array}$ \\
\hline$n$ & 4,320 & 887 \\
\hline Age (years) & $53(9)$ & $57(8)$ \\
\hline $\begin{array}{l}\text { Duration of diag- } \\
\text { nosed diabetes } \\
\text { (years) }\end{array}$ & 0 & $2.6(0.5)$ \\
\hline Sex (male) & $60 \%$ & $58 \%$ \\
\hline \multicolumn{3}{|l|}{ Ethnic group } \\
\hline White Caucasian & $82 \%$ & $87 \%$ \\
\hline Afro-Caribbean & $8 \%$ & $7 \%$ \\
\hline Asian-Indian & $10 \%$ & $6 \%$ \\
\hline \multicolumn{3}{|l|}{ Smoking } \\
\hline Never & $35 \%$ & $35 \%$ \\
\hline Ex-smoker & $34 \%$ & $44 \%$ \\
\hline Current smoker & $31 \%$ & $21 \%$ \\
\hline BMI $\left(\mathrm{kg} / \mathrm{m}^{2}\right)$ & $27.7(5.3)$ & $29.5(5.5)$ \\
\hline $\begin{array}{l}\mathrm{HbA}_{1 \mathrm{c}}(\%), \text { median } \\
\text { (interquartile range) }\end{array}$ & $6.9(6.0-8.0)$ & $6.5(5.8-7.6)$ \\
\hline SBP (mmHg) & $135(20)$ & 154 (16) \\
\hline $\begin{array}{l}\text { Diastolic BP } \\
(\mathrm{mmHg})\end{array}$ & $83(10)$ & $90(8)$ \\
\hline $\begin{array}{l}\text { Total cholesterol } \\
(\mathrm{mmol} / \mathrm{l})\end{array}$ & $5.4(1.0)$ & $5.6(1.0)$ \\
\hline $\begin{array}{l}\text { HDL-cholesterol } \\
(\mathrm{mmol} / \mathrm{l})\end{array}$ & $1.07(0.24)$ & $1.08(0.25)$ \\
\hline $\begin{array}{l}\text { LDL-cholesterol } \\
(\mathrm{mmol} / \mathrm{l})\end{array}$ & $3.5(1.0)$ & $3.6(1.0)$ \\
\hline $\begin{array}{l}\text { Triglycerides } \\
(\mathrm{mmol} / \mathrm{l}) \text {, geometric } \\
\text { mean (1 SD range) }\end{array}$ & $1.5(0.9-2.5)$ & $1.9(0.9-4.1)$ \\
\hline $\begin{array}{c}\text { Albuminuria } \\
(>50 \mathrm{mg} / \mathrm{l})\end{array}$ & $13.4 \%$ & $17.3 \%$ \\
\hline
\end{tabular}

Measurements were made following the dietary run-in period and data are shown as mean (SD) except where indicated 
Fig. 1 Incidence of UKPDS composite endpoints in 4,320 patients, as rate per 1,000 person-years. a Any diabetesrelated endpoint, $\mathbf{b}$ diabetesrelated deaths, $\mathbf{c}$ all-cause mortality, $\mathbf{d}$ myocardial infarction, e microvascular disease, f stroke. Values are for 16 different combinations of updated mean $\mathrm{HbA}_{1 \mathrm{c}}$ and updated mean SBP. Unadjusted rates are shown for the three primary and three secondary composite endpoints


rates per 1,000 person-years using a life-table approach with log-rank tests. Only composite endpoints that occurred following a patient's randomisation into the BP control study were included. A trend test was used to compare the composite endpoint incidence rates according to whether patients had been allocated to both an intensive glucose and tight BP control policy, either of these alone or neither.

\section{Results}

Patients

Patient characteristics, following their dietary run-in period, are shown in Table 1. Updated mean $\mathrm{HbA}_{1 \mathrm{c}}$ and SBP 1 st to 99th percentiles were $4.6-11.2 \%$ and $85-$ $230 \mathrm{mmHg}$, respectively, in the 4,320 patients included in the observational analyses. Median $\mathrm{HbA}_{1 \mathrm{c}}$ and SBP values for their respective four categories were 5.5, 6.5, 7.5 and $9.0 \%$ and $119,135,144$ and $162 \mathrm{mmHg}$ with 
Table 2 Median $\mathrm{HbA}_{1 \mathrm{c}}$ and $\mathrm{SBP}$ values for the four highest and lowest category combinations of updated mean $\mathrm{Hb} \mathrm{A}_{1 \mathrm{c}}$ and updated mean SBP

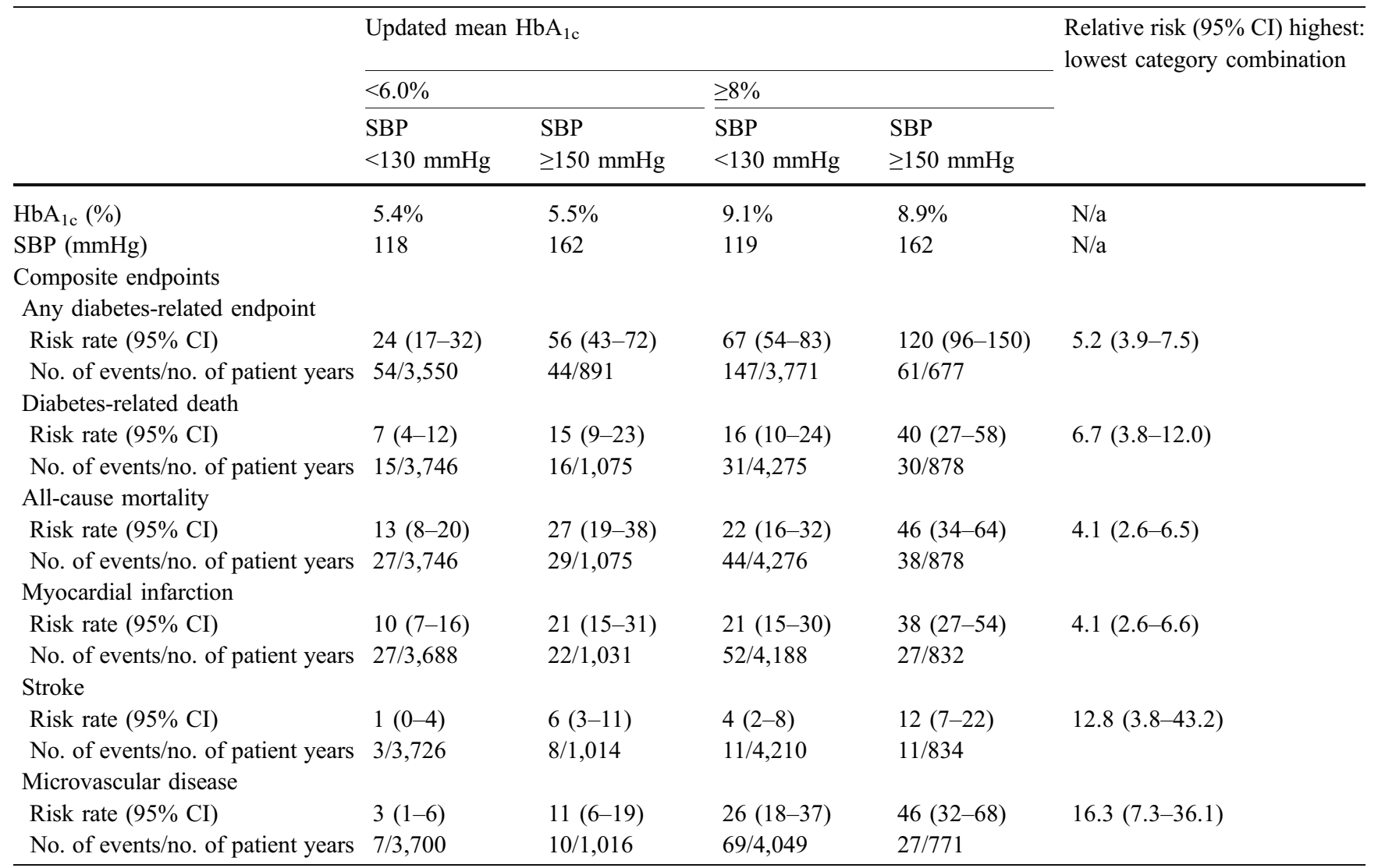

The left-hand section shows the composite endpoint absolute risk rates per 1,000 person-years adjusted in a Poisson model to white Caucasian male sex, age 50-54 years and diabetes duration 7.5-12.5 years, and the number of events and number of person-years for each category. On the right: the relative risk of the highest $\left(\mathrm{HbA}_{1 \mathrm{c}} \geq 8 \%, \mathrm{SBP} \geq 150 \mathrm{mmHg}\right)$ to the lowest $\left(\mathrm{HbA} \mathrm{Ac}_{\mathrm{c}}<6.0 \%\right.$, SBP $\left.<130 \mathrm{mmHg}\right)$ category combination

corresponding person-years of observation being 9,785 , 13,589, 9,538 and 10,646 and 15,881, 9,428, 7,938 and 10,311 . The 887 patients included in both the blood glucose and BP intervention arms of the trial had been diabetic for a mean of 2.6 years, tended to be older at diagnosis of diabetes, to have a greater BMI and to have a higher BP than those included in the observational analyses.

\section{Unadjusted incidence rates}

The crude composite endpoint incidence rates in the 16 category combinations of updated $\mathrm{HbA}_{1 \mathrm{c}}$ and updated SBP for the three primary and the three secondary composite endpoints are shown in Fig. 1. The incidence of the 'any diabetes-related endpoint' in the lowest $\left(\mathrm{HbA}_{1 \mathrm{c}}<6.0 \%\right.$, SBP $<130 \mathrm{mmHg})$ and highest $\left(\mathrm{HbA}_{1 \mathrm{c}} \geq 8 \%\right.$, SBP $\geq 150 \mathrm{mmHg}$ ) category combinations was 15 and 82 per 1,000 person-years, respectively. The incidence in the other two extreme category combinations $\left(\mathrm{HbA}_{1 \mathrm{c}}<6.0 \%\right.$, SBP $\geq 150 \mathrm{mmHg}$ and $\mathrm{HbA}_{1 \mathrm{c}} \geq 8 \%, \mathrm{SBP}<130 \mathrm{mmHg}$ ) was 43 and 39 per 1,000 person-years, respectively. A gradation of increasing incidence of composite endpoints as exposure to $\mathrm{HbA}_{1 \mathrm{c}}$ and SBP increased was observed. A similar pattern was seen for each of the other primary and secondary composite endpoints.

\section{Adjusted incidence rates}

Table 2 shows Poisson model adjusted composite endpoint rates for the four extreme $\mathrm{HbA}_{1 \mathrm{c}}$ and $\mathrm{SBP}$ category combinations. As for the unadjusted rates, the incidence of composite endpoints increased with increasing updated mean $\mathrm{HbA}_{1 \mathrm{c}}$ and SBP exposure. Comparing the highest with the lowest $\mathrm{HbA}_{1 \mathrm{c}}$ and SBP category combination, there was an approximately four-fold increase in the rate of myocardial infarction, whereas for microvascular disease the increase was approximately 16-fold.

\section{Potential additive effect of glycaemia and BP}

Table 3 shows the risk reductions calculated for a $1 \%$ decrement in updated mean $\mathrm{HbA}_{1 \mathrm{c}}$ and for a $10 \mathrm{mmHg}$ decrement in updated mean SBP. For the 'any diabetesrelated endpoint' these were $21 \%$ (95\% CI 19-24\%) and $11 \%$ (95\% CI 9-13\%), respectively. The interaction test 
indicated that the effects of updated mean $\mathrm{HbA}_{1 \mathrm{c}}$ and updated mean SBP on composite endpoints were additive, apart from the microvascular disease endpoint, where their effects were sub-additive $(p<0.0001)$.

Patients randomised to both the glycaemic and BP intervention arms of the trial

Table 4 shows data for the 887 hypertensive UKPDS patients who were randomised in both the glycaemic and the BP arms of the trial. The proportions allocated to each of the four possible blood glucose and BP control policy combinations who developed any of the three primary composite endpoints are shown and their relative risks compared with those randomised to a conventional glucose control policy and to less tight BP control policy. Figure 2 shows these data as the incidence per 1,000 person-years. For the 'any diabetes-related endpoint' those allocated to the intensive glucose and to the tight BP control policies had fewer events than those allocated to either policy alone or neither ( $p$ for trend 0.024). Similar trends were seen for the diabetes-related deaths and all-cause mortality composite endpoints. To examine the potential confounding effect of randomised therapies with updated mean $\mathrm{HbA}_{1 \mathrm{c}}$ and SBP the model was re-run for the 589 patients with the requisite data available. No significant differences were seen in any of the results obtained.

\section{Discussion}

This study shows that the risk of developing type 2 diabetic complications is independently and additively associated with previous exposure to hyperglycaemia and hypertension. Patients with higher levels of both $\mathrm{HbA}_{1 \mathrm{c}}$ and SBP were at greater risk than those with just one of these risk factors raised and at much greater risk than those with neither of them raised. For example, those patients with an updated mean $\mathrm{HbA}_{1 \mathrm{c}} \geq 8.0 \%$ and an updated mean SBP $\geq 150 \mathrm{mmHg}$ had an approximately four-fold increased risk of myocardial infarction and 16-fold risk of developing microvascular disease compared with those with updated mean values of $\mathrm{HbA}_{1 \mathrm{c}}<6.0 \%$ and $\mathrm{SBP}<130 \mathrm{mmHg}$. The effects of updated mean $\mathrm{HbA}_{1 \mathrm{c}}$ and SBP on incidence rates of composite endpoints were shown to be additive in an adjusted proportional hazards model, suggesting strongly that to minimise the risk of diabetic complications it is necessary to treat both blood glucose and BP aggressively. The results obtained in the intervention trial were consistent with the observational data showing that those patients allocated to both intensive glucose and tight BP control policies tended to have fewer events than those allocated to either policy alone or neither ( $p$ for trend 0.024).

The adjusted absolute risk rates for composite endpoints seen with exposure to differing levels of updated mean $\mathrm{HbA}_{1 \mathrm{c}}$ and updated mean SBP confirm our previously published observational analyses for the associations seen with $\mathrm{HbA}_{1 \mathrm{c}}$ and $\mathrm{SBP}$ values measured shortly after diagnosis of diabetes $[3,4]$. The analyses presented here differ in that simultaneous adjustments have been made for both updated mean $\mathrm{HbA}_{1 \mathrm{c}}$ and updated mean SBP values. The unadjusted incidence rates for the composite endpoints show a gradation of increasing risk with increasing $\mathrm{HbA}_{1 \mathrm{c}}$ and SBP values, with no evidence of a threshold effect for any of the composite endpoints with differing combinations of updated mean $\mathrm{HbA}_{1 \mathrm{c}}$ and SBP categories.

A combination of diabetes and hypertension is known to give an increased risk of cardiovascular mortality [14-17], but these studies were too small in duration or size to allocate risks by categories. Our data confirm the increasing risk of cardiovascular disease with hyperglycaemia and hypertension as well as showing that the risk is additive when they co-exist. The Framingham study reported that the incidence of cardiovascular disease was substantially increased in diabetic compared with non-diabetic subjects

Table 3 Risk reductions in 3,418 UKPDS patients

$\begin{array}{ll}\begin{array}{l}\text { Number of } \\ \text { endpoints }\end{array} & \begin{array}{l}\text { Risk decrease per } 1 \% p \\ \text { decrement in updated } \\ \text { mean } \mathrm{HbA}_{1 \mathrm{c}}(95 \% \mathrm{CI})\end{array}\end{array}$

Risk decrease $p \quad p$ for interaction
per $10 \mathrm{mmHg}$
decrement in
updated mean
SBP $(95 \% \mathrm{CI})$

Primary composite endpoints

Any diabetes-related endpoin

Diabetes-related death

1,172
325

All-cause mortality

556

Secondary composite endpoints

Myocardial infarction

Stroke

461

Microvascular disease

$$
\begin{aligned}
& 21 \%(17-24) \\
& 22 \%(16-28) \\
& 14 \%(11-19) \\
& 14 \%(8-19) \\
& 11 \%(0-21) \\
& 37 \%(33-41)
\end{aligned}
$$

$\begin{array}{clll}<0.0001 & 11 \%(9-13) & <0.0001 & 0.028 \\ <0.0001 & 16 \%(12-20) & <0.0001 & 0.11 \\ <0.0001 & 12 \%(9-16) & <0.0001 & 0.74 \\ & & & \\ <0.0001 & 11 \%(7-15) & <0.0001 & 0.68 \\ 0.045 & 18 \%(13-23) & <0.0001 & 0.075 \\ <0.0001 & 10 \%(7-14) & <0.0001 & <0.0001\end{array}$

Risks reductions were calculated for a $1 \%$ decrement in updated mean $\mathrm{HbA}_{1 \mathrm{c}}$ and a $10-\mathrm{mmHg}$ decrement in updated mean SBP using a proportional hazards model adjusted for sex, age at diagnosis, ethnicity, smoking, HDL-cholesterol, LDL-cholesterol, triglycerides and albuminuria. A product term for $\mathrm{HbA}_{1 \mathrm{c}}$ and SBP was included in the model to test for possible interactions with a $1 \%$ level of significance chosen to avoid potential Type 1 errors. Non-statistically significant product terms are indicative of additive effects 


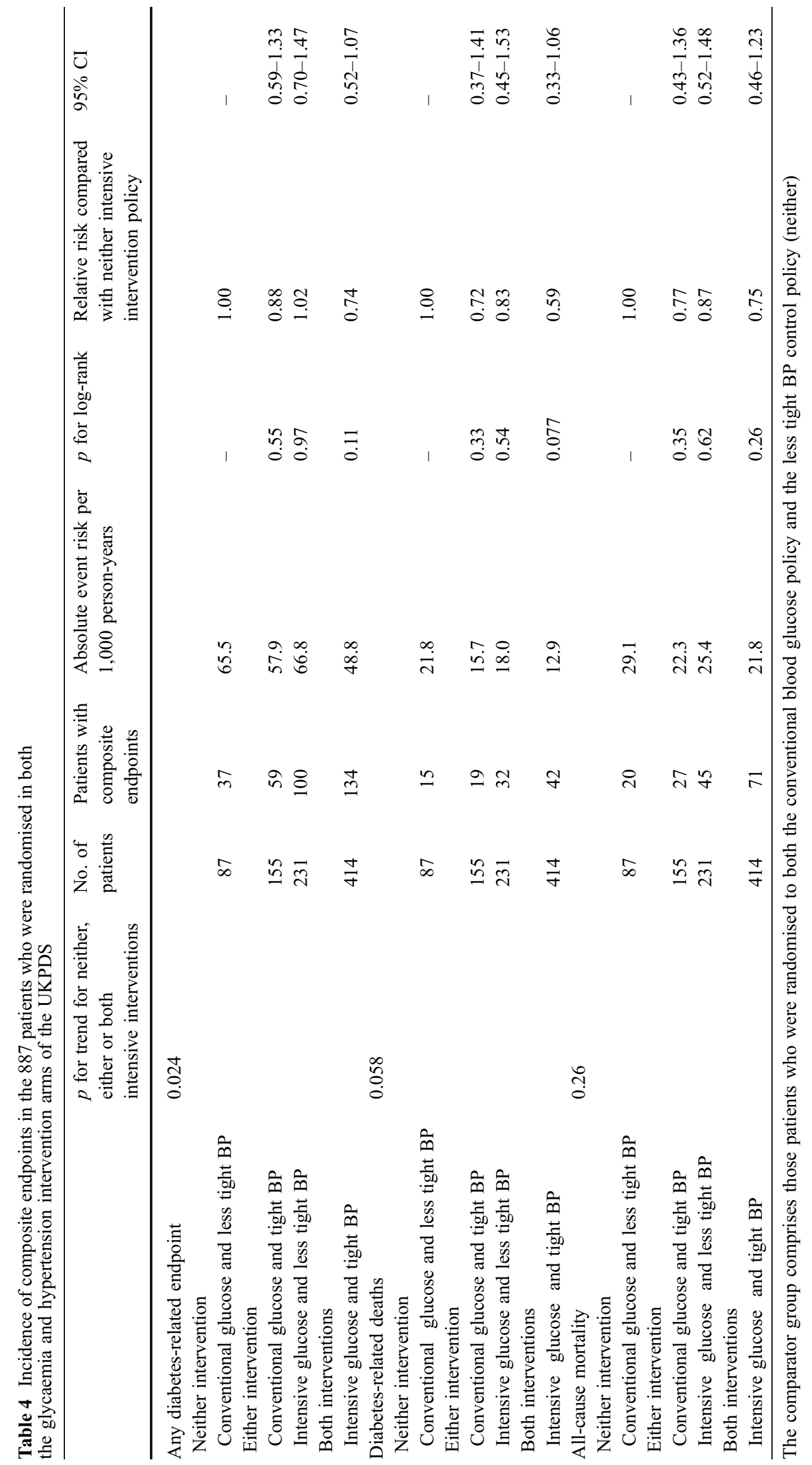


[18]. Dyslipidaemia and smoking, which have been shown to be major risk factors for coronary artery disease [19, 20], were included as covariates in the analyses presented here. Moreover, we estimated the absolute and relative risks at several different levels of glycaemic and BP exposure, rather than by the broader classes used by some previous studies [21-23] and examined the effects on both the macrovascular and microvascular complications of diabetes.

For all composite endpoints, the risk associated with the combination of elevated blood glucose and BP is as least as great as the sum of the individual exposures. For diabetesrelated deaths, all-cause mortality, myocardial infarction and stroke, the combined glycaemia and BP effects were additive. This finding is in accord with other studies [7]. For microvascular endpoints, however, this relationship was sub-additive, suggesting that the deleterious effects of hyperglycaemia and hypertension are not as great at elevated levels of each other as they are at lower levels of the other risk factor. This may be due to pre-existing tissue damage that cannot deteriorate further.

The risk reduction trends seen with the $\mathrm{HbA}_{1 \mathrm{c}}$ and $\mathrm{SBP}$ decreases obtained in the clinical trial are consistent with the observational data presented here. Direct comparisons between the trial and observational data should be undertaken cautiously as only hypertensive individuals were included in the BP-lowering arm of the UKPDS. The median $\mathrm{HbA}_{1 \mathrm{c}}$ and SBP differences between randomised policy groups reflect the central tendencies of the $\mathrm{HbA}_{1 \mathrm{c}}$ and SBP distributions obtained, whereas the observational analyses were based on selection of patients between limits of exposure defined by $1 \% \mathrm{HbA}_{1 \mathrm{c}}$ and $10 \mathrm{mmHg} \mathrm{SBP}$ intervals. The observational analyses also contain considerably more data $(43,558$ person-years $)$ than the combined trial analysis of randomised BP and glycaemic control policies $(9,184$ person-years). The UKPDS was designed to address separately the degree to which clinical outcomes in type 2 diabetes might be improved by more intensive treatment of blood glucose or BP, and was not powered to evaluate whether simultaneous improvement of these two risk factors might be additive. The small number of patients included in both the blood glucose and BP interventions means that there is insufficient statistical power to provide definitive answers with respect to an approach that improves blood glucose and BP simultaneously. We await with interest the results of the ongoing Action to Control Cardiovascular Risk in Diabetes (ACCORD) (http://www.accordtrial.org/public/index.cfm) and Action in Diabetes and Vascular Disease: PreterAx and DiamicroN MR Controlled Evaluation (ADVANCE) [24] studies, both of which are examining in a factorial design the impact of improved blood glucose and BP control on macrovascular outcomes in people with type 2 diabetes.

The results of the observational analyses presented here are likely to be generalisable to patients with newly diagnosed type 2 diabetes. Whilst the UKPDS excluded people with a recent myocardial infarction, there is no reason to believe that the associations shown here with glycaemia and BP would be any different in these individuals. The commonest reason for not entering the study was lack of interest, with only $28 \%$ being excluded for other reasons [9]. It is not clear whether these results would be applicable to the elderly, e.g. over 70 years, as the upper age limit for entry to the UKPDS was 65 years. Although hypertension has been assessed here using SBP, similar results were obtained using diastolic BP (data not shown). The absolute event rates reported here are lower than might be expected for people with type 2 diabetes, possibly because UKPDS patients were newly diagnosed, aged 65 or below, did not have a history of a recent myocardial infarction or life-threatening disease at entry and received additional health care as participants in a clinical trial [9].

Our data have major clinical relevance, since more than half of patients with type 2 diabetes have $\mathrm{HbA}_{1 \mathrm{c}}$ values $>8.0 \%$ [25], and almost as many may have SBP values $>150 \mathrm{mmHg}$ [25]. Since therapy of each of the risk factors is known to reduce the risk of complications $[1,5,6,26]$, and the presence of both risk factors markedly increases the risk over the presence of just one, there is potential for achieving a major reduction in the incidence of the complications of diabetes by treating both blood glucose and BP. The data presented here are further evidence for taking a view of prevention based on assessment of overall risk of complications rather than on that assessed from individual risk factors [7], particularly now that the coronary heart disease risks can be calculated specifically for people with type 2 diabetes $[27,28]$. The concordance of the intervention trial data with the observational analyses indicates that optimal therapy of both elevated blood glucose and elevated BP is essential to help minimise the risk of diabetic complications in type 2 diabetes.

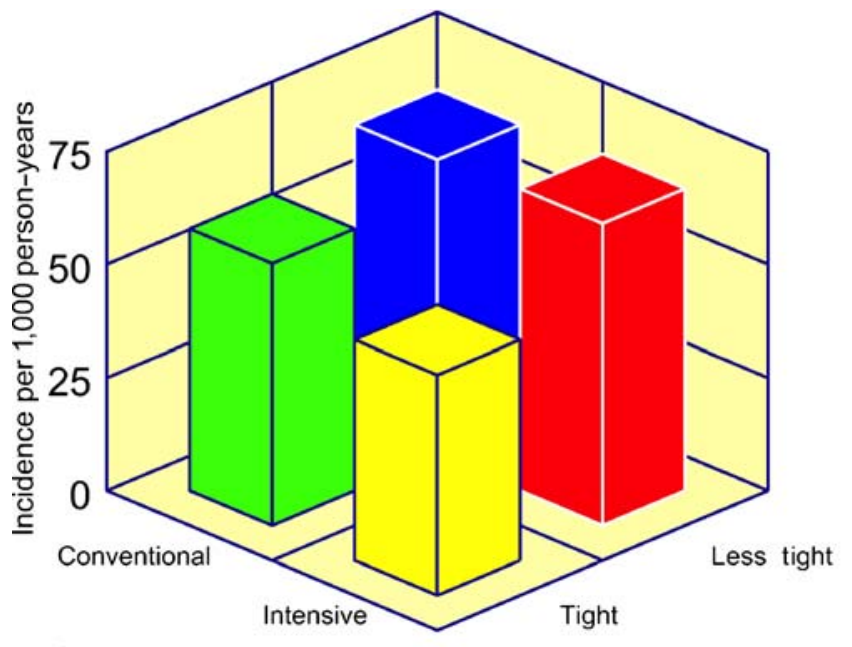

Glucose control

Blood pressure contro

Fig. 2 Incidence of the UKPDS primary composite 'any diabetesrelated endpoint' by intention-to-treat, as rate per 1,000 personyears, in the 887 patients randomised in a factorial design between the four different interventions: a conventional or intensive glucose control policy and a less tight or tight BP control policy. Only endpoints that occurred following each patient's randomisation into the BP control study are included. Those allocated to both the intensive glucose and the tight BP control policies had fewer events than those allocated to either policy alone or to neither ( $p$ for trend 0.024) 
Acknowledgements The late Professor R. C. Turner designed and was the inspiration for the UKPDS. The cooperation of the patients and many NHS and non-NHS staff at the centres is much appreciated. We would like to thank H. McElroy and S. E. Manley for their assistance in the production of this manuscript. The major grants for this study were from the UK Medical Research Council, British Diabetic Association, the UK Department of Health, The National Eye Institute and The National Institute of Digestive, Diabetes and Kidney Disease in the National Institutes of Health, USA, The British Heart Foundation, Novo-Nordisk, Bayer, Bristol Myers Squibb, Hoechst, Lilly, Lipha and Farmitalia Carlo Erba. Other funding companies and agencies, the supervising committees, and all participating staff are listed in an earlier paper [1]. Funding bodies did not participate in writing the paper.

Duality of interest None of the authors have any relevant dualities of interest to declare.

\section{References}

1. UKPDS Group (1998) Intensive blood glucose control with sulphonylureas or insulin compared with conventional treatment and risk of complications in patients with type 2 diabetes (UKPDS 33). Lancet 352:837-853

2. Turner R, Cull C, Holman R (1996) UKPDS 17: a 9-year update of a randomized, controlled trial on the effect of improved metabolic control on complications in non-insulindependent diabetes mellitus. Ann Intern Med 124:136-145

3. Stratton IM, Adler AI, Neil HAW et al (2000) UKPDS 35 Association of glycaemia with macrovascular and microvascular complications of type 2 diabetes: prospective observational study. BMJ 321:405-412

4. UKPDS Group (2000) Association of systolic blood pressure with macrovascular and microvascular complications of type 2 diabetes (UKPDS 36). BMJ 321:412-419

5. Ohkubo Y, Kishikawa H, Araki E et al (1995) Intensive insulin therapy prevents the progression of diabetic microvascular complications in Japanese patients with non-insulin-dependent diabetes mellitus: a randomized prospective 6-year study. Diabetes Res Clin Pract 28:103-117

6. Heart Outcomes Prevention Evaluation Study Investigators (2000) Effects of ramipril on cardiovascular and microvascular outcomes in people with diabetes mellitus: results of the HOPE study and MICRO-HOPE substudy. Lancet 355:253-259

7. Ramsay LE, Williams B, Johnston GD et al (1999) British Hypertension Society guidelines for hypertension management 1999: summary. BMJ 319:630-635

8. Gaede P, Vedel P, Larsen N, Jensen G, Parving H-H, Pedersen O (2003) Multifactorial intervention and cardiovascular disease in patients with type 2 diabetes. N Engl J Med 348:383-393

9. UK Prospective Diabetes Study Group (1991) UK Prospective Diabetes Study VIII: study design, progress and performance. Diabetologia 34:877-890

10. UK Prospective Diabetes Study Group (1998) Efficacy of atenolol and captopril in reducing risk of macrovascular and microvascular complications in type 2 diabetes: UKPDS 39. BMJ 317:713-720

11. UK Prospective Diabetes Study Group (1998) Tight blood pressure control and risk of macrovascular and microvascular complications in type 2 diabetes: UKPDS 38. BMJ 317: 703-713
12. UK Prospective Diabetes Study Group (1994) UK Prospective Diabetes Study XI: biochemical risk factors in type 2 diabetic patients at diagnosis compared with age-matched normal subjects. Diabet Med 11:534-544

13. Cull CA, Manley SE, Stratton IM, Holman RR, Turner RC, Matthews DR (1997) Approach to maintaining comparability of biochemical data during long-term clinical trials. Clin Chem 43:1913-1918

14. Pan WH, Cedres LB, Liu K et al (1986) Relationship of clinical diabetes and asymptomatic hyperglycaemia to risk of coronary heart disease mortality in men and women. Am J Epidemiol 123:504-516

15. Barrett-Connor EL, Cohn BA, Wingard DL, Edelstein SL (1991) Why is diabetes mellitus a stronger risk factor for fatal ischemic heart disease in women than in men? JAMA 265: 627-631

16. Stamler J, Vaccaro O, Neaton JD, Wentworth D (1993) Diabetes, other risk factors, and 12 year cardiovascular mortality for men screened in the Multiple Risk Factor Intervention Trial. Diabetes Care 16:434-444

17. Hanefeld M, Fischer S, Julius U et al (1996) Risk factors for myocardial infarction and death in newly detected NIDDM: the Diabetes Intervention Study, 11-year follow-up. Diabetologia 39:1577-1583

18. Wilson PW, Cupples LA, Kannel WB (1991) Is hyperglycaemia associated with cardiovascular disease? The Framingham Study. Am Heart J 121:586-590

19. UKPDS Group (1998) Risk factors for coronary artery disease in non-insulin dependent diabetes (UKPDS 23). BMJ 316 : $823-828$

20. Rosengren A, Welin L, Tsipogianni A, Wilhelmsen L (1989) Impact of cardiovascular risk factors on coronary heart disease among middle aged diabetic men: a general population study. BMJ 299:1127-1131

21. Haffner SM, Mitchell BD, Stern MP, Hazuda HP (1991) Macrovascular complications in Mexican Americans with type II diabetes. Diabetes Care 14:665-671

22. Moss SE, Klein R, Klein BEK, Meuer SM (1994) The association of glycemia and cause-specific mortality in a diabetic population. Arch Intern Med 154:2473-2479

23. Manson JAE, Colditz GA, Stampfer MJ et al (1991) A prospective study of maturity-onset diabetes mellitus and risk of coronary heart disease and stroke in women. Arch Intern Med 151:1141-1147

24. ADVANCE Collaborative Group (2005) ADVANCE-Action in Diabetes and Vascular Disease: patient recruitment and characteristics of the study population at baseline. Diabet Med 22:882-888

25. Harris MI, Cowie CC, Stern MP, Boyko EJ, Reiber GE, Bennett PH (eds) (1995) Diabetes in America. National Institutes of Health, National Institute of Diabetes and Digestive and Kidney Diseases, Washington, District of Columbia

26. Shorr RI, Franse LV, Resnick HE, Bari MD, Johnson KC, Pahor M (2000) Glycemic control of older adults with type 2 diabetes: findings from the third national health and nutrition examination survey, 1988-1994. J Am Geriatr Soc 48:264-267

27. Stevens R, Adler A, Gray A, Briggs A, Holman R (2000) Lifeexpectancy projection by modelling and computer simulation (UKPDS 46). Diabetes Res Clin Pract 50(Suppl 3):S5-S13

28. UKPDS Group (2001) The UKPDS Risk Engine: a model for the risk of coronary heart disease in type 2 diabetes (UKPDS 56). Clin Sci 101:671-679 